\title{
Plasmodium knowlesi transmission: integrating quantitative approaches from epidemiology and ecology to understand malaria as a zoonosis
}

\author{
P. M. BROCK ${ }^{1} *$ K. M. FORNACE ${ }^{2}$, M. PARMITER ${ }^{1}$, J. COX ${ }^{2}$, C. J. DRAKELEY ${ }^{2}$, \\ H. M. FERGUSON ${ }^{1} \dagger$ and R. R. $\mathrm{KAO}^{1} \dagger$ \\ ${ }^{1}$ Institute of Biodiversity Animal Health and Comparative Medicine, College of Medical Veterinary and Life Sciences, \\ University of Glasgow, Glasgow, UK \\ ${ }^{2}$ London School of Hygiene and Tropical Medicine, London, UK
}

(Received 5 October 2015; revised 1 December 2015; accepted 2 December 2015; first published online 28 7anuary 2016)

\section{SUMMARY}

The public health threat posed by zoonotic Plasmodium knowlesi appears to be growing: it is increasingly reported across South East Asia, and is the leading cause of malaria in Malaysian Borneo. Plasmodium knowlesi threatens progress towards malaria elimination as aspects of its transmission, such as spillover from wildlife reservoirs and reliance on outdoor-biting vectors, may limit the effectiveness of conventional methods of malaria control. The development of new quantitative approaches that address the ecological complexity of $P$. knowlesi, particularly through a focus on its primary reservoir hosts, will be required to control it. Here, we review what is known about $P$. knowlesi transmission, identify key knowledge gaps in the context of current approaches to transmission modelling, and discuss the integration of these approaches with clinical parasitology and geostatistical analysis. We highlight the need to incorporate the influences of fine-scale spatial variation, rapid changes to the landscape, and reservoir population and transmission dynamics. The proposed integrated approach would address the unique challenges posed by malaria as a zoonosis, aid the identification of transmission hotspots, provide insight into the mechanistic links between incidence and land use change and support the design of appropriate interventions.

Key words: malaria, mosquito, vector, zoonosis, Plasmodium knowlesi, macaque, infectious disease transmission, mathematical model, $R_{0}$, reproduction number.

\section{INTRODUCTION}

Plasmodium knowlesi, a malaria parasite of monkeys in South East Asia, was identified as an emergent public health threat in 2004 (Singh et al. 2004). Previously, P. knowlesi in humans was known only from experimental infections carried out for clinical research on neurosyphilis (Collins, 2012), and what was presumed to be a single anomalous spillover event (Chin et al. 1965; Vythilingam, 2012). However, there has been a recent increase in the number of human $P$. knowlesi cases reported, particularly in Malaysia (William et al. 2013, 2014). The majority of these have been reported in Sarawak and Sabah, where P. knowlesi is now the most common cause of clinical malaria (William et al. 2013), but cases have also been widely documented in Peninsula Malaysia (Yusof et al. 2014). Although Malaysia has achieved malaria preelimination status (World Health Organisation, 2014), there is concern that P. knowlesi may hinder

* Corresponding author. Institute of Biodiversity Animal Health and Comparative Medicine, College of Medical Veterinary and Life Sciences, University of Glasgow, Glasgow, UK. E-mail: paddy.brock@glasgow.ac.uk

$\dagger$ These authors contributed equally to this work. further progress towards elimination (William et al. 2013).

Outside Malaysia, human P. knowlesi cases have been reported from across South East Asia (CoxSingh and Singh, 2008; Moyes et al. 2014; Cramer, 2015). However, as diagnosis by microscopy has been rarely confirmed by molecular techniques in regions other than Malaysian Borneo, the overall human burden of $P$. knowlesi infection may be substantially underestimated (Moyes et al. 2014). Although artemisinin-based combination therapies clear P. knowlesi parasites effectively, a high proportion of patients with $P$. knowlesi develop severe malaria (William et al. 2011; Barber et al. 2013), and infection can be fatal (Cox-Singh et al. 2008; Rajahram et al. 2012).

Genetic evidence suggests that $P$. knowlesi derives from an ancestral parasite population that predates the human settlement of South East Asia and, therefore, that $P$. knowlesi may have spilled over into humans prior to 2004, but was misidentified as Plasmodium malariae (Lee et al. 2009a, 2011). Even considering changes in diagnostics and surveillance, notifications of $P$. knowlesi cases in Malaysian Borneo have increased since 2004, which may reflect an increase in incidence (William et al. 2014). Land use change has been suggested as a key driver of this

Parasitology (2016), 143, 389-400. C Cambridge University Press 2016. This is an Open Access article, distributed under the terms of the Creative Commons Attribution licence (http://creativecommons.org/licenses/by/4.0/), which permits unrestricted re-use, distribution, and reproduction in any medium, provided the original work is properly cited. 
increase (Cox-Singh and Singh, 2008), and a recent analysis provides the first evidence for this, indicating that forest cover and loss are associated with $P$. knowlesi incidence (Fornace et al. 2016). It has also been suggested that $P$. knowlesi incidence has increased due to a loss of cross-protective immunity following successful control of Plasmodium vivax and Plasmodium falciparum in Malaysian Borneo (Cox-Singh, 2012; Barber et al. 2013), an effect that could act in combination with the influence of land use change, but for which there is little evidence at present (William et al. 2013).

Land use change has been hypothesized to influence malaria incidence through a variety of mechanisms (Guerra et al. 2006). In the case of $P$. knowlesi, this could involve effects on humans, vectors, primary reservoir hosts - Long-tailed (Macaca fascicularis) and Pig-tailed macaques (Macaca nemestrina) - and their interactions. For example, changes to human behaviour associated with land-use change could bring humans into closer contact with forest-associated anopheline vectors (Collins, 2012; Barber et al. 2013). Migration to new areas may increase contact between humans and the $P$. knowlesi forest transmission cycle, giving rise to 'frontier' malaria (De Castro et al. 2006). A further possibility is that land-use change influences the transmission dynamics of $P$. knowles $i$ in a more fundamental way, through effects on the life-history, population dynamics or behaviour of the reservoir host, vector or both. For example, deforestation may cause macaques to crowd into remaining forest patches (Chapman et al. 2005; Fooden, 1995), spend more time on the ground (Singh et al. 2001) and alter their ranging behaviour and microhabitat use (Riley, 2008). Macaques may also seek out human settlements to raid crops or forage around houses (Chapman and Peres, 2001; Hambali et al. 2012), bringing them closer to people. The abundance and community composition of vectors is also associated with land use (Chang et al. 1997; Overgaard et al. 2003; Petney et al. 2009; Brant, 2011), and vectors may reproduce, survive and bite at different rates in anthropogenically altered habitats (Chang et al. 1997; Patz et al. 2000; De Castro et al. 2006).

The large age range of $P$. knowlesi patients and the existence of family clusters of cases suggest that transmission may occur peri-domestically (Barber et al. 2012). Human-to-human transmission of $P$. knowlesi has been demonstrated experimentally (Chin et al. 1968), and P. knowlesi gametocytes are formed during human infections (Lee et al. 2009b; Van Hellemond et al. 2009). However, there is - so far - no evidence from the field of natural humanvector-human transmission (Kantele and Jokiranta, 2011; Vythilingam, 2012; Grigg et al. 2014a; Ramasamy, 2014). The higher number of P. knowlesi genotypes found in macaques compared with humans is consistent with this, as it suggests a higher transmission rate in macaques relative to humans, as does the lack of clustering of P. knowlesi genotypes in either host species (Lee et al. 2011; Divis et al. 2015; Millar and Cox-Singh, 2015).

Here we discuss quantitative approaches to understanding $P$. knowlesi transmission, with an emphasis on mathematical models of transmission, and how they relate to empirical-statistical approaches such as those used to map infectious disease risk. We identify knowledge gaps, and discuss how efforts towards the integration of clinical parasitology, geostatistical analysis and the mathematical modelling of transmission dynamics may yield insight into the epidemiology of $P$. knowlesi. The goal of such efforts should be to identify the determinants of $P$. knowles $i$ infection risk in an ecological context, so that they can be effectively mitigated to reduce the associated burden of disease.

QUANTITATIVE APPROACHES TO

UNDERSTANDING $P$. KNOWLESI TRANSMISSION

Mathematical models have contributed fruitfully to the understanding of infectious disease transmission (Heesterbeek and Roberts, 2015; Heesterbeek et al. 2015), and much of the research effort on controlling mosquito-borne disease during the last century has focused on the development of transmission models (Mandal et al. 2011; Smith et al. 2012; Reiner et al. 2013; Wallace et al. 2014). Contemporary malaria models are increasingly geared towards including the geographical, ecological and epidemiological heterogeneities that influence transmission. These models can address questions about the relative merits of interventions (e.g., Griffin et al. 2010), and have played an important role in reducing mortality and morbidity around the world (World Health Organisation, 2014). However, a recent review (Reiner et al. 2013) revealed that most mosquitoborne disease models are strikingly similar as they share central assumptions made by the earliest malaria models, collectively referred to as RossMacDonald. These drove the development of pathogen transmission theory, the formulation of metrics such as $R_{0}$ and vectorial capacity, and allowed for prediction of the effectiveness of mosquito-borne disease control (MacDonald et al. 1968; Smith et al. 2012). However, the assumptions of Ross-MacDonald models make them less applicable to the transmission of diseases with complex ecologies such as P. knowlesi.

The simplest way to include a wildlife reservoir in a Ross-MacDonald model is by adding a nonhuman host compartment, allowing for hostspecific transmission rates, and this was the approach taken by an early transmission model of $P$. knowlesi (Yakob et al. 2010). There is growing general interest in understanding how different host species 
contribute to the persistence of pathogens in multihost systems, so that control can be appropriately targeted (Haydon et al. 2002; Fenton and Pedersen, 2005; Streicker et al. 2013; Viana et al. 2014). To describe $P$. knowlesi transmission in the context of this trend in disease ecology and test the broad plausibility of natural human-vector-human transmission, we developed a scenario exploration tool for this review using a model similar to Yakob et al. 2010. Following Imai et al. (2014), we assessed $P$. knowlesi transmission scenarios with variable levels of human-vector-human transmission according to their human and macaque equilibrium prevalences (Box 1). The results suggest that natural human-vector-human transmission of $P$. knowles is plausible, but that it is likely to be rare, which is consistent with previous work (Imai et al. 2014).

\section{Spatial distribution of hosts and vectors}

Although useful for illustrative scenario exploration, the simplifying assumptions of models such as that used in Box 1 mean they are unable to incorporate fundamental aspects of $P$. knowlesi transmission. For example, they assume that host populations are well mixed, and that mosquitoes feed randomly on vertebrate hosts (Reiner et al. 2013; Perkins et al. 2013). However, human populations are unlikely to be homogenously mixed with either the forestassociated vectors of $P$. knowlesi, or macaque reservoir hosts (Jiram et al. 2012; Wong et al. 2015). The omission of spatial variation from models of systems in which it is has an important influence on transmission can bias estimation of epidemiological parameters (Meyers et al. 2005; Riley, 2007; Riley et al. 2015). Spatial variation may be particularly important to include in models of zoonoses (Alexander et al. 2012, 2015) and vector-borne disease (Perkins et al. 2013), as their transmission involves multiple species with distinct ecologies. Therefore, ignoring heterogeneity in the spatial distribution of hosts, vectors and vector-biting patterns could introduce problematic bias into analysis and prediction of $P$. knowlesi transmission.

Efforts to incorporate spatial heterogeneity into understanding of $P$. knowlesi transmission have drawn on research into dengue and yellow fever, which like $P$. knowlesi are vector-borne and have forest transmission cycles (Gubler, 2004; Vasilakis et al. 2011). Imai et al. (2014) modelled transmission across three zones (forest, farm and village), in which the relative abundance of macaque and human hosts was varied. Macaques were assumed to range across the forest and farm zones, humans were assumed to be present in the farm and village zones, and a separate vector population was modelled in each zone. The model predicted that humans were at greatest risk of $P$. knowlesi infection when macaques were present in sufficient numbers in both the forest and
Box 1. Modelling transmission scenarios

To describe $P$. knowlesi transmission in terms of disease ecology, a Ross-MacDonald-type model was used to compare the plausibility of transmission scenarios with variable rates of human-vector-human transmission. Following Yakob et al. (2010) and Imai et al. (2014), a differential equation model tracked the proportions of infected macaques, vectors and humans through time. The daily vector mortality rate $(g=0 \cdot 15)$, the extrinsic incubation period $(T=10$ days $)$, and the daily mammalian recovery rate $(r=0.07)$ were fixed at values considered typical for human malarias for lack of suitable data on $P$. knowlesi. To take into account variation in remaining variables and parameters, 100000 sets of values were sampled from the following ranges using Latin hypercube sampling: number of humans, $H$, (2000-200 000); number of macaques, $M$, (2000$200000)$; number of vectors, $V$, (2000-200 000); transmission coefficients: vector-human, $C_{v h}$, (0-1), vector-macaque, $C_{v m},(0-1)$, humanvector, $C_{h v},(0-1)$, macaque-vector, $C_{m v},(0-1)$; vector-biting preference for humans vs macaques, $p,(0-1)$; biting rate (per mosquito per day), $b,(0-7)$.

Models were initiated with infection prevalences of 1,0 and $0 \%$ in the vector, macaque and human populations, respectively, and run to equilibrium for each scenario. Parameter sets were considered to be plausible if they generated equilibrium prevalences of $0 \cdot 5-5 \%$ in humans (based on empirical data from crosssectional surveys and active case detection in Kudat, Sabah [Fornace et al. 2015]) and 50$90 \%$ in macaques. The macaque prevalence range was intentionally broad, given the limited and variable nature of available estimates (Vythilingam et al. 2008; Jeslyn et al. 2011; Lee et al. 2011). In a departure from previous $P$. knowlesi models, we calculated the average number of secondary human infections caused by a single macaque infection, $R^{\mathrm{MH}}$, and by a single human infection, $R^{\mathrm{HH}}$, for each scenario:

$$
\begin{gathered}
R^{\mathrm{MH}}=\frac{V}{M} b(1-p) \frac{V}{H} b p\left(c_{m v} c_{v h}\right) \exp (-g T) \frac{1}{g r} \\
R^{\mathrm{HH}}=\left(\frac{V}{H} b p\right)^{2}\left(c_{h v} c_{v h}\right) \exp (-g T) \frac{1}{g r}
\end{gathered}
$$

$R_{0}$ for each scenario was calculated as the dominant eigenvalue of the next generation matrix (NGM; Diekmann et al. 2010; BrooksPollock and Wood, 2015): 


$$
N G M=\left(\begin{array}{ll}
R^{\mathrm{HH}} & R^{\mathrm{HM}} \\
R^{\mathrm{MH}} & R^{\mathrm{MM}}
\end{array}\right)
$$

where

$$
\begin{aligned}
& R^{\mathrm{HM}}=\frac{V}{H} b p \frac{V}{M} b(1-p)\left(c_{h v} c_{v m}\right) \exp (-g T) \frac{1}{g r} \\
& R^{\mathrm{MM}}=\left(\frac{V}{M} b(1-p)\right)^{2}\left(c_{m v} c_{v m}\right) \exp (-g T) \frac{1}{g r}
\end{aligned}
$$

The observed asymmetrical distribution of system $R_{0}$ (Fig. 1a) is as expected, given that $R^{\mathrm{HH}}$ is an element of the primary, while $R^{\mathrm{MH}}$ is an element of the secondary, diagonal of the NGM. 1837 of 100000 scenarios generated plausible human and macaque prevalences. $R^{\mathrm{HH}}$ was greater than one in ten of these plausible scenarios (Fig. 1b), $R^{\mathrm{MM}}$ was less than one in eight of these plausible scenarios, and both of these conditions were met in only two plausible scenarios. These results suggest that human infections are more likely to result from zoonotic transmission, but that natural human-vectorhuman transmission cannot be ruled out, and that humans are unlikely to play a role in parasite maintenance. This is consistent with previous work (Imai et al. 2014) and builds on it by estimating the relative contributions of each host species to transmission.

Plausible scenarios were characterised by high numbers of humans, low vector-human transmission, high vector-macaque transmission and low human-biting preference (Fig. 1c, d). The few plausible scenarios in which $R^{\mathrm{HH}}$ was greater than 1 were characterized by high numbers of vectors, and a combination of low vector-human and macaque-vector transmission with high vector-macaque and human-vector transmission (Fig. 1c, d).

Although designed for demonstration rather than inference, this model shows how key aspects of $P$. knowlesi transmission could be identified and used to inform control and surveillance programmes. For example, high numbers of vectors may increase the risk that sustained human-to-human transmission emerges. In this case, the influence of land use change on vector population dynamics may be an important determinant of human disease risk, and vector control may be an effective intervention option.

the farm zones, as this allowed for the maintenance of infection in the forest, and its dissemination to humans at farms (Imai et al. 2014). The explicit consideration of the interface between the forest transmission cycle of $P$. knowlesi and the at-risk human population lays valuable groundwork for the identification of the key interactions that determine human infection risk. However, compartmental zonation does not take into account the heterogeneous spatial co-distribution of habitats or land use types in, for example, Malaysian Borneo, where farming practices and settlement proximity to forest are variable. Therefore, to understand $P$. knowlesi transmission dynamics in space, research will need to look beyond a compartmental modelling framework.

One way to capture fine-scale spatial variation in infectious disease risk is using advanced cartographic techniques, such as occurrence mapping and modelbased geostatistics (Patil et al. 2011; Hay et al. 2013; Pigott et al. 2015; Dalrymple et al. 2015). In contrast to mechanistic transmission models (such as RossMacDonald), these methods use empirical models (i.e., statistical models that do not make assumptions about mechanism) to quantify the association between disease occurrence or transmission metrics and spatially dependent explanatory variables. These models vary in form and can take into account the auto-correlated nature of spatial data, and other sources of bias such as unevenly distributed variation (Pullan et al. 2012; Hay et al. 2013; Wardrop et al. 2014). Such mapping techniques have been widely used to predict infectious disease risk by estimating transmission metrics (e.g., Clements et al. 2006; Hay et al. 2009; Vounatsou et al. 2009; Gething et al. 2011; Lau et al. 2012; Raso et al. 2012; Wardrop et al. 2013; Grimes and Templeton, 2015; Lai et al. 2015) and occurrence (e.g., Bhatt et al. 2013; Cano et al. 2014; Gilbert et al. 2014; Pigott et al. 2014; Messina et al. 2015; Mylne et al. 2015) in space, and have been used to guide disease control policy and practice (e.g., Diggle et al. 2007; Magalhães et al. 2011). However, these techniques are not problem-free as they make implicit assumptions about the systems to which they are fitted (Wardrop et al. 2014). The most relevant of these assumptions for $P$. knowlesi is that the disease being mapped is assumed to be in equilibrium with its environment. To some extent, this can be dealt with by iteratively refitting models as new data become available (e.g., Gething et al. 2011; http://www.abraid.ox.ac.uk). For diseases that are not at equilibrium, though, iteratively re-fitting models that do not incorporate a mechanistic description of transmission may not lead to a cumulatively clearer picture of risk (Wood et al. 2015). Widespread and rapid land use change of the kind currently occurring in Malaysian Borneo (Langner et al. 2007; Bryan et al. 2013; Fornace et al. 2014) could give rise to this kind of unstable epidemiology. Therefore, insight from both empirical and mathematical modelling approaches (Karesh et al. 2012) will be required to understand 
spatial heterogeneity in human risk of $P$. knowlesi infection.

A constructive way in which quantitative methods from across disciplines may be integrated is through the development of new types of vector-borne disease transmission models. Increasing recognition of the importance of heterogeneity in aspects of vector-borne disease transmission supports an argument for 'recasting' standard models by switching their focus from transmission onto host and vector movement, and the ecological and social variation that drive them (Smith et al. 2014). Such a shift in emphasis could simultaneously address the problems of the uneven distribution of vector bites amongst vertebrate hosts, non-random mixing of hosts and vectors, and finite host population sizes, which are not taken into account (simultaneously) by current models (Perkins et al. 2013). This approach may be particularly applicable to the investigation of zoonotic infections such as $P$. knowlesi: due to constraints on the flexibility of models to incorporate their interface, transmission models of zoonoses have tended to focus either on dynamics in the reservoir or outbreaks in the target population (Lloyd-Smith et al. 2009; Lloyd-Smith et al. 2014). The re-organization of model mechanics proposed by Smith et al. (2014) may allow for the simultaneous estimation of reservoir transmission dynamics, spillover events, and onward transmission in the target population. In addition, it may allow for the incorporation of stochasticity, which is particularly important for systems in which rare events (e.g., spillover) may have high impact (LloydSmith et al. 2005; Smith, 2008; King et al. 2015). However, although promising, it remains to be seen whether the requisite fine-scale spatial data on $P$. knowlesi host and vector movement will be available, and therefore whether this data-intensive approach will provide further insight into the dynamics of $P$. knowlesi transmission.

\section{Spatial scales of transmission}

Epidemiological and ecological processes that influence zoonotic disease transmission operate over different spatial scales; for example, on average humans move over greater distances than mosquitoes. In addition to variability in the static spatial distribution of hosts and vectors discussed above, variation in their movement is likely to have an important influence on vector-borne disease transmission. This is because it affects contact between individuals, the distances over which parasite is moved, and the spatial scales over which individuals interact with the environment.

Compartmental models of malaria transmission, such as Ross-MacDonald, implicitly assume that mixing between hosts and vectors is homogenous at a defined spatial scale. The results of such models, therefore, are likely to be misleading if related to real world scenarios in which spatial scale assumptions are unjustified; for example, if an area into and out of which hosts migrate is modelled as self-contained. Bias introduced by the spatial scale assumptions of transmission models has been shown to interact with the degree of clustering of hosts in space (Perkins et al. 2013), and how it influences the estimation of transmission metrics such as incidence is likely to vary between pathogen-host systems (Mills and Riley, 2014; Riley et al. 2015). For vector-borne pathogens and zoonoses, such as P. knowlesi, the multiplicity of spatial scales implicated in transmission may be particularly problematic, as they involve multiple species with varied ecologies (Lambin et al. 2010; Ben-Ari et al. 2011; Johnson et al. 2015).

To illustrate the challenge spatial scale presents to understanding transmission, we used data from a case-control study carried out in Kudat, Malaysian Borneo (Grigg et al. 2014a) to analyse how the strength of association between key environmental variables and human $P$. knowlesi infection status varied with scale (Box 2). The results show that different environmental variables were most strongly related to infection status when summarized over areas of different sizes. The exercise illustrates how spatial scales that characterize transmission may be identified, and suggests that incorporating multiple scales into inferential and predictive analysis of $P$. knowlesi transmission may be beneficial. In addition, this approach could be used for designing disease interventions: the scale at which the density of aquatic breeding sites was most strongly associated with infection status, for example, could inform the deployment of larvicidal control.

\section{CHALLENGES AND OPPORTUNITIES}

\section{Data gaps}

Data on human $P$. knowlesi infection are accumulating, particularly in Malaysian Borneo, and understanding of the clinical epidemiology of P. knowlesi is improving (Daneshvar et al. 2009; Barber et al. 2012, 2013; William et al. 2013, 2014; Grigg et al. $2014 a, b$ ). However, most data are from hospitals and clinics, and there is a shortage of communitybased estimates of human infection patterns. Therefore, P. knowlesi transmission is only beginning to be understood in the ecological context of spillover from wildlife (Fornace et al. 2016). The major challenge facing this effort is the unbiased collection of data on human infections, reservoir hosts and vectors of $P$. knowlesi of sufficient geographical spread for integration into a generalized model of $P$. knowlesi transmission. This review has focusses on the details of the quantitative methods that might be used for this integration, but without the 

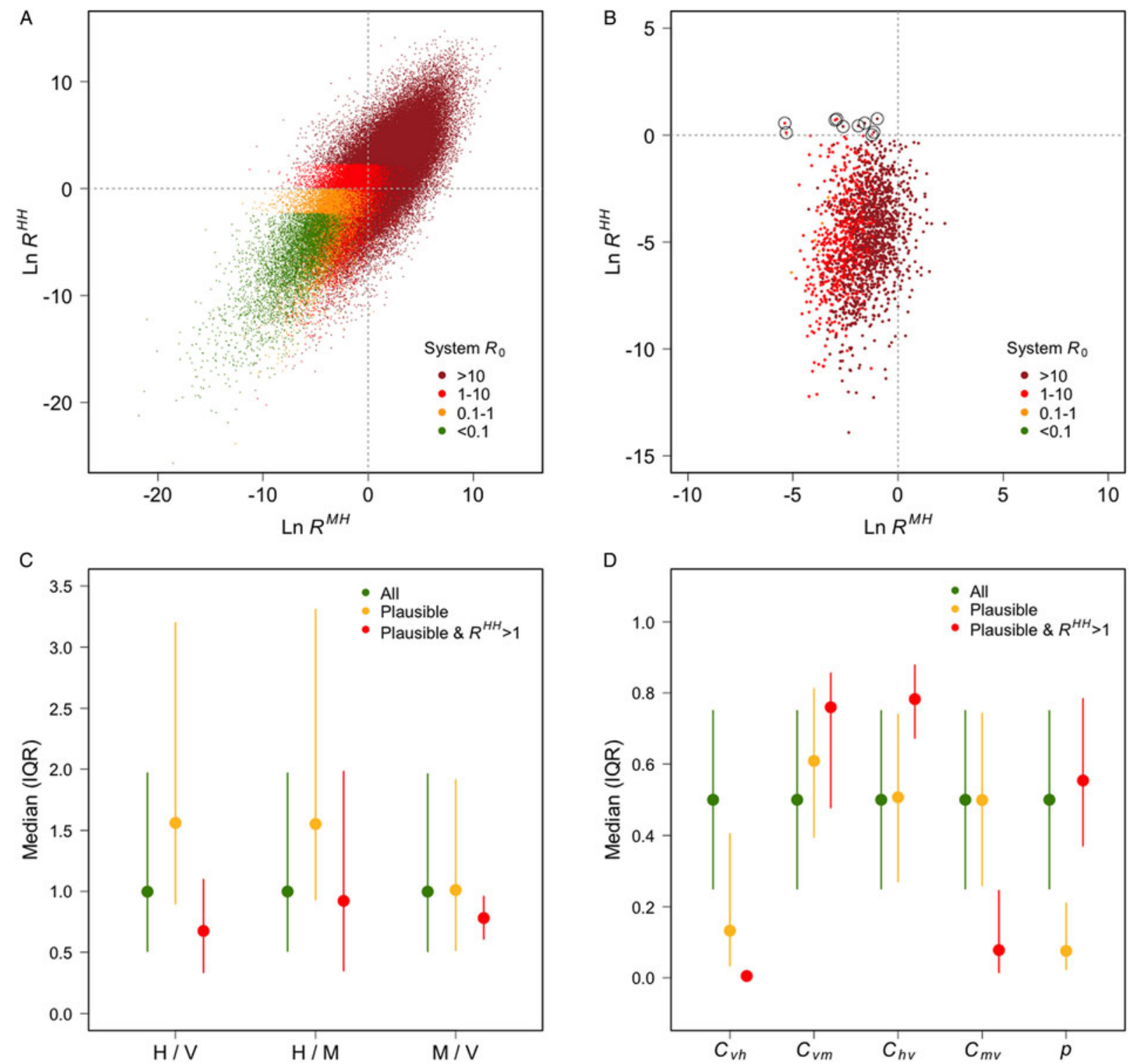

Fig. 1. (A) The average number of secondary human infections caused by a single macaque case ( $x$-axis) and by a single human case ( $y$-axis), and system $R_{0}$ (colours), for each scenario; (B) the same information plotted only for scenarios that generated prevalences deemed plausible (humans: $0 \cdot 5-5 \%$; macaques: $50-90 \%$ ), scenarios in which $R^{\mathrm{HH}}$ was $>1$ are circled; (C) the medians and interquartile ranges of the ratios of humans to vectors, humans to macaques and macaques to vectors for all scenarios, plausible scenarios, and plausible scenarios in which $R^{\mathrm{HH}}>1$; (D) the median and interquartile ranges of the four transmission coefficients: $C_{v h}$ (vector-human), $C_{v m}$ (vector-macaque), $C_{h v}$ (human-vector) $C_{m v}$ (macaquevector); and the vector-biting preference for humans vs macaques $(p)$.

requisite data, the approaches discussed may not be feasible.

Studies of $P$. knowlesi in macaques suggest that prevalence is particularly high in Malaysia and Long-tailed macaques (Vythilingam et al. 2008; Lee et al. 2011). However, published P. knowlesi prevalence estimates in macaques are based on small numbers of individuals and are variable. In addition, there are few data available on macaque population densities, and how these vary across the geographical range of $P$. knowlesi, which would be required to put prevalence estimates into epidemiological context (Fooden, 1995; Moyes et al. 2014). Additionally, data on the habitat preferences, movement patterns and social dynamics of macaques will be necessary for predictions about $P$. knowlesi transmission in future scenarios of land use change. At present, the data available are either not sufficiently specific to P. knowlesi (e.g., Chapman and Peres, 2001; Singh et al. 2001; Chapman et al. 2005; Riley, 2008) or too geographically limited to allow for generalization (e.g., Hambali et al. 2012). Macaque data would also allow for deeper exploration of the biting preferences of $P$. knowlesi vectors, through better estimates of host availability. If $P$. knowlesi infectious bites fall on humans because macaques are temporarily absent - and other biteable mammals are permanently absent from 
Box 2. Spatial scale of environmental risk factors

To illustrate the problem of variable influence on transmission across multiple spatial scales, we used data from a case-control study in Kudat, Malaysian Borneo (Grigg et al. 2014a) to explore how the strength of association between key environmental features and human $P$. knowlesi infection status changed with spatial scale. Forest cover and loss variables were extracted from classified satellite data (Hansen et al. 2013) for neighbourhoods of varying size (radii $2 \cdot 1-5 \cdot 5 \mathrm{~km}$ ) around households where $P$. knowlesi was reported. To compare with case household locations, the same forest variables were extracted from neighbourhoods around points randomly sampled in space (pseudoabsences, Barbet-Massin et al. 2012) from inside the catchment area of the case-control study. A threshold of $>50 \%$ canopy cover was used to define forest, and the four variables calculated were: proportional forest loss (2000-2012), fragmentation of forest lost (perimeter area ratio, 2000-2012), proportional forest cover (2012) and fragmentation of cover (perimeter area ratio, 2012). Each environmental variable was fitted as the only explanatory variable in a generalized additive model of infection probability (case $v s$ pseudo-absence) for all neighbourhood sizes $(2 \cdot 1-5 \cdot 5 \mathrm{~km})$.

Figure 2a shows neighbourhoods of three example sizes around a household. Figure $2 \mathrm{~b}$ shows how the strength of the association between environmental variables and infection status changes with spatial scale, and that the scales at which variables have the strongest association with infection status are different. Forest loss was most strongly associated with infection status when summarized over an area with radius $5.5 \mathrm{~km}$, while forest cover was most strongly associated with infection status when summarized over an area with radius of $3.5 \mathrm{~km}$. This analysis is designed to demonstrate the problem of multiple spatial scales for understanding and predicting $P$. knowlesi disease risk. The question of how combinations of relevant spatial scales might be incorporated into analysis and prediction is discussed in the main text, but remains a challenge, and will be the focus of future work.

degraded forest (Civitello et al. 2015; Keesing and Ostfeld, 2015; McCallum, 2015) - this could have implications for interventions aimed at lowering human infection risk, particularly if macaque movement patterns are influenced by human movement patterns.
Similar data gaps exist for vectors, but the challenges associated with addressing them are different. The geographical diversity of the region across which $P$. knowlesi has been reported means extrapolation between areas is inadvisable (Ahmed and CoxSingh, 2015). This is especially true for vector ecology, as the principal Anopheles species responsible for $P$. knowlesi transmission varies locally and between regions. The vectors of $P$. knowlesi belong to the Anopheles leucophyrus group: An. hackeri has been incriminated in Selangor; An. introlatus in Hulu Selangor; An. cracens in Kuala Lipis; An. latens in Sarawak; An. balabacensis in Sabah; and An. dirus in Vietnam (Vythilingam et al. 2006, 2008, 2014; Tan et al. 2008; Marchand et al. 2011; Jiram et al. 2012; Wong et al. 2015). Reliable data on vector abundance and behaviour as required to estimate vectorial capacity are limited, and the information that is available is drawn from such different settings that generalization is inadvisable (e.g., Jiram et al. 2012; Wong et al. 2015). Although there are some data on how the diversity, abundance and life history of $P$ knowles $i$ vectors vary between habitats and respond to anthropogenic disturbance (Chang et al. 1997; Petney et al. 2009; Brant, 2011; Wong et al. 2015), they are not yet detailed or geographically diverse enough to inform predictions of human $P$. knowlesi infection risk under scenarios of future land use change.

In addition, there is little available data on land use to put data on $P$. knowlesi hosts and vectors into geographical context. The collection of land use data of sufficient resolution over sufficiently large areas is challenging given the speed of land-use change in parts of $P$. knowlesi's range, particularly in Malaysian Borneo (Fornace et al. 2014). In addition, the classification of such remotely sensed data poses a problem given that the ecotypes relevant for $P$. knowlesi transmission are - as yet unknown; the land use categories that best describe variation in macaque behaviour, for example, are likely to be different from those that best describe variation in mosquito life history.

Finally, it is important to consider the added complexity of human behaviour, and how it relates to land use change, and might interplay with other influences on P. knowlesi transmission to determine risk.

\section{Opportunities}

Acquisition of detailed data on macaques and vectors across broad geographic scales will require randomized sampling. The same is true of data on humans, which could be achieved by carrying out cross-sectional surveys, and by incorporating $P$. knowlesi screening into existing surveys. This would have numerous benefits such as allowing for the distinction between human and non-human drivers of infection, and taking into account case- 


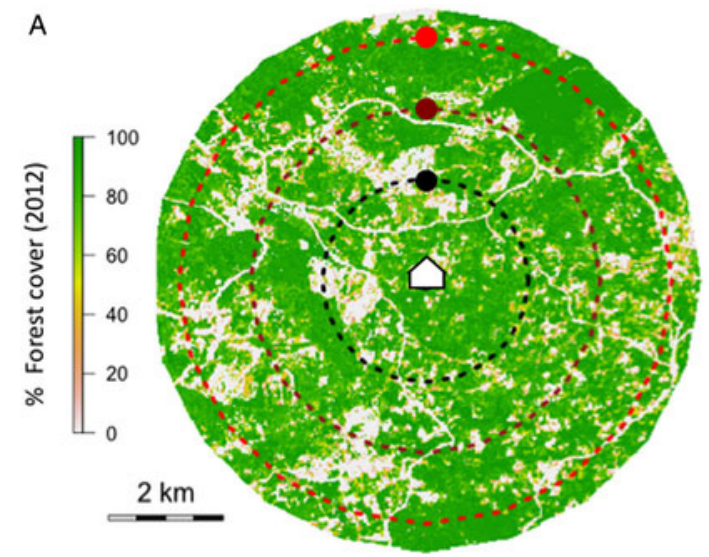

B

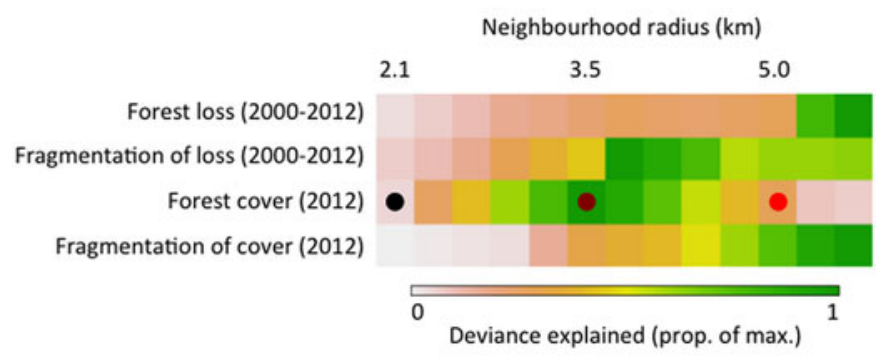

Fig. 2. (A) Three example neighbourhood sizes drawn around a case household, showing \% forest cover in 2012, and (B) the deviance explained by four example forest variables at 13 neighbourhood sizes in univariate generalized additive models of infection status.

reporting bias (Barber et al. 2012, 2013; William et al. 2013, 2014; Grigg et al. 2014a). New techniques for P. knowlesi diagnosis (Millar and Cox-Singh, 2015) mean randomized sampling would provide data on asymptomatic $P$. knowlesi infection in humans (e.g., Van den Eede et al. 2010; Cox-Singh, 2012), which would allow for more accurate estimates of human exposure. It would also allow for estimates of exposure using serology, for which $P$. knowlesi-specific assays are currently being developed. Relevant serological markers maximize the information derived per sample, as antibody responses last longer than infection, and information from markers with different time signatures can be combined (e.g., Helb et al. 2015). The ability to control for sampling effort would broaden the scope of genetic studies aimed at tracking parasite diversity and transmission (e.g., Noviyanti et al. 2015), and provide the necessary tools for surveillance of natural human-vectorhuman transmission. Currently, genetic studies on P. knowlesi (e.g., Lee et al. 2011; Divis et al. 2015) use opportunistically collected samples that represent parasite populations to an unknown degree. A randomized sampling design would also allow for the use of more powerful quantitative analysis tools. For example, model-based geostatistical techniques require spatial data on the absence as well as presence of infection, and a broader geographical spread of data would confer greater predictive power. If sufficient environmental variation were incorporated into sampling designs, environmental interpolation would equate to geographical extrapolation, allowing for risk estimation outside of the study area (Matthiopoulos et al. 2011; Gilbert et al. 2014). Together, the above illustrates the many potential benefits of the incorporation of randomized sampling into data collection efforts on $P$. knowlesi.

Research on zoonotic $P$. knowlesi necessitates the integration of a wider range of disciplines than human malarias. Mathematical models are useful tools for such interdisciplinary integration (McKenzie, 2000), as has been recognized since the earliest days of malaria epidemiology: 'The aim of mathematical epidemiology is to integrate biological and circumstantial data into one coherent whole' (MacDonald, 1957). The study of $P$. knowlesi transmission represents an opportunity to link functional ecology with mathematical epidemiology, and combine the strengths of the empirical-statistical approaches largely used by the former with those of the mechanistic models largely used by the latter. The incorporation of functional ecology into descriptions of $P$. knowlesi transmission of the kind being called for in vector-borne disease research in general (Smith et al. 2014; Hartemink et al. 2014) and malaria research in particular (Ferguson et al. 2010; Godfray, 2013; Perkins et al. 2013), could inform the design of disease control programs, and provide insight into the processes of zoonotic emergence, the implications of which could be significant beyond $P$. knowlesi.

Functional ecology can be incorporated into predictions of infectious disease risk through analytical focus on the biological resources necessary for pathogens to complete their life cycles (Hartemink et al. 2014; Killeen et al. 2014). This has the advantages of introducing a spatial dimension often lacking from mathematical models of human malaria transmission and taking into account biological mechanisms often lacking from ecological statistics (Hartemink et al. 2014). As applied to $P$. knowlesi, the multiple spatial scales implicated in transmission complicate the incorporation of resource-dependence into spatial predictions of infection risk. However, this multi-scale problem has been identified in other areas of ecological research, including prediction of animal habitat use (Beyer et al. 2010), and analytical tools have been developed to deal with it (e.g., Matthiopoulos et al. 2011). One such method with potential application to $P$. knowlesi frames animal habitat use in the context of availability (Aarts et al. 2013), whereby, for example, the use of forest by macaques on one scale (e.g., a zone of 
radius of $1 \mathrm{~km})$ is dependent on its availability on another (e.g., a zone of radius $5 \mathrm{~km}$ ). The application of such an estimation framework to prediction of $P$. knowlesi infection risk would allow both for the variable influence of environmental factors across spatial scales, and for the possibility that environmental factors may have important influences on more than one spatial scale.

Any method seeking insight into $P$. knowles $i$ transmission needs to consider how fast the landscape is changing in parts of $P$. knowlesi's range, particularly in Sabah and Malaysian Borneo (Langner et al. 2007; Bryan et al. 2013; Fornace et al. 2014). Another development of ecological theory that could be usefully applied to this problem for predicting $P$. knowlesi infection risk is research into the links between animal habitat use and population dynamics (Morales et al. 2010; Matthiopoulos et al. 2015). Animals use habitat in different ways depending on their population density and whether it is changing (Matthiopoulos et al. 2015). Therefore, if land use change impacts the population densities of mosquitoes and macaques, this may change not only how they are distributed in space, but also the parameters and functional forms that define their distribution in relation to environmental variables. This could have an important influence on human infection risk in an area of rapid land use change such as Malaysian Borneo, and adoption of ecological modelling approaches may be the key to understanding the environmentally dependent epidemiology of zoonoses such as P. knowlesi. Such approaches may even be applicable to quantifying human movement and habitat use, and could be explored as a way of plugging sociological studies into an integrated framework for understanding $P$. knowlesi transmission.

\section{Concluding remarks}

Clinical investigation has advanced understanding of $P$. knowlesi epidemiology. To move towards prediction of human infection risk, the next phase of $P$. knowlesi research should focus on its ecology. Aspects of spatial variation in $P$. knowlesi infection risk have begun to be mapped on a broad spatial scale (Moyes et al. 2014), and P. knowlesi has been identified as a priority disease for future mapping efforts (Pigott et al. 2015). Although infectious disease mapping of this kind brings many advantages (Hay et al. 2013), given the rapid rates of landscape change in areas where human risk of $P$. knowlesi appears highest, efforts to understand and control $P$. knowlesi transmission will benefit from work on the mechanisms that give rise to spatial patterns of infection risk to complement their empiricalstatistical description through mapping. If sufficient appropriate data are available, and spatial heterogeneities can be accounted for, such mechanistic models would confer greater power for extrapolation and prediction, and allow for more effective identification of risk groups and areas, optimization of intervention deployment, and surveillance for natural humanvector-human transmission.

\section{ACKNOWLEDGEMENTS}

The authors would like to thank Beth Downe, Albert Lim, Tommy Abidin and the MONKEYBAR team.

\section{FINANCIAL SUPPORT}

The authors (PB, KF, MP, JC, CD, HF and RK) acknowledge the Medical Research Council, Natural Environment Research Council, Economic and Social Research Council, and Biotechnology and Biosciences Research Council for the funding received for this project through the Environmental and Social Ecology of Human Infectious Diseases Initiative (ESEI) (Grant number G1100796).

\section{REFERENCES}

Aarts, G., Fieberg, J., Brasseur, S. and Matthiopoulos, J. (2013). Quantifying the effect of habitat availability on species distributions. Fournal of Animal Ecology 82, 1135-1145.

Ahmed, M. A. and Cox-Singh, J. (2015). Plasmodium knowlesi - an emerging pathogen. ISBT Science Series 10 (Suppl.), 134-140.

Alexander, K. A., Lewis, B. L., Marathe, M., Eubank, S. and Blackburn, J. K. (2012). Modeling of wildlife-associated zoonoses: applications and caveats. Vector-borne and Zoonotic Diseases 12, 1005-1018.

Alexander, K. A., Sanderson, C.E., Marathe, M., Lewis, B. L., Rivers, C. M., Shaman, J., Drake, J. M., Lofgren, E., Dato, V. M., Eisenberg, M. C. and Eubank, S. (2015). What factors might have led to the emergence of ebola in West Africa? PLoS Neglected Tropical Diseases 9, e0003652.

Barber, B. E., William, T., Dhararaj, P., Anderios, F., Grigg, M. J., Yeo, T.W. and Anstey, N. M. (2012). Epidemiology of Plasmodium knowlesi malaria in north-east Sabah, Malaysia: family clusters and wide age distribution. Malaria fournal 11, 401

Barber, B. E., William, T., Grigg, M. J., Menon, J., Auburn, S., Marfurt, J., Anstey, N. M. and Yeo, T. W. (2013). A prospective comparative study of knowlesi, falciparum, and vivax malaria in Sabah, Malaysia: high proportion with severe disease from Plasmodium knowlesi and Plasmodium vivax but no mortality with early referral and artesunate therapy. Clinical Infectious Diseases 56, 383-397.

Barbet-Massin, M., Jiguet, F., Albert, C. H. and Thuiller, W. (2012). Selecting pseudo-absences for species distribution models: how, where and how many? Methods in Ecology and Evolution 3, 327-338.

Ben-Ari, T., Neerinckx, S., Gage, K. L., Kreppel, K., Laudisoit, A., Leirs, H. and Stenseth, N. C. (2011). Plague and climate: scales matter. PLoS Pathogens 7, e1002160.

Beyer, H. L., Haydon, D. T., Morales, J. M., Frair, J. L., Hebblewhite, M., Mitchell, M. and Matthiopoulos, J. (2010). The interpretation of habitat preference metrics under use-availability designs. Philosophical Transactions of the Royal Society of London B 365, 2245-2254.

Bhatt, S., Gething, P. W., Brady, O. J., Messina, J. P., Farlow, A. W., Moyes, C. L., Drake, J.M., Brownstein, J.S., Hoen, A. G., Sankoh, O., Myers, M.F., George, D. B., Jaenisch, T., Wint, G. R. W., Simmons, C. P., Scott, T. W., Farrar, J. J. and Hay, S. I. (2013). The global distribution and burden of dengue. Nature 496, 504-507. Brant, H. L. (2011). Changes in abundance, diversity and community composition of mosquitoes based on different land use in Sabah, Malaysia. Thesis, MSc, Imperial College London. http://www.safeproject.net/projects/biodiversity/diversity-and-composition/changes-in-

abundance-diversity-and-community-composition-of-mosquitoes-basedon-different-land-use-in-sabah-malaysia-msc/

Brooks-Pollock, E. and Wood, J. L. N. (2015). Eliminating bovine tuberculosis in cattle and badgers: insight from a dynamic model. Proceedings of the Royal Society B Biological Sciences 282, 20150374.

Bryan, J. E., Shearman, P. L., Asner, G. P., Knapp, D. E., Aoro, G. and Lokes, B. (2013). Extreme differences in forest degradation in Borneo: comparing practices in Sarawak, Sabah, and Brunei. PLoS ONE 8. doi: 10.1371/journal.pone.0069679. 
Cano, J., Rebollo, M.P., Golding, N., Pullan, R. L., Crellen, T., Soler, A., Hope, L. A. K., Lindsay, S. W., Hay, S. I., Bockarie, M. J. and Brooker, S. J. (2014). The global distribution and transmission limits of lymphatic filariasis: past and present. Parasites $\sigma^{\circ}$ Vectors 7, 466. Chang, M. S., Hii, J., Buttner, P. and Mansoor, F. (1997). Changes in abundance and behaviour of vector mosquitoes induced by land use during the development of an oil palm plantation in Sarawak. Transactions of the Royal Society of Tropical Medicine and Hygiene $\mathbf{9 1}$ 382-386.

Chapman, C. A. and Peres, C. A. (2001). Primate conservation in the new millennium: the role of scientists. Evolutionary Anthropology 10, 16-33. Chapman, C. A., Gillespie, T. R. and Speirs, M. L. (2005). Parasite prevalence and richness in sympatric colobines: effects of host density. American Fournal of Primatology 67, 259-266.

Chin, W., Contacos, P., Collins, W., Jeter, M. and Alpert, E. (1968). Experimental mosquito-transmission of Plasmodium knowlesi to man and monkey. American Fournal of Tropical Medicine and Hygiene 17, 355-358. Chin, W., Contacos, P. G., Coatney, G. R. and Kimball, H. R. (1965). A naturally acquired quotidian-type malariain man transferable to monkeys. Science 149, 865.

Civitello, D. J., Cohen, J., Fatima, H., Halstead, N. T., Liriano, J., McMahon, T. A., Ortega, C. N., Sauer, E. L., Sehgal, T., Young, S. and Rohr, J. R. (2015). Biodiversity inhibits parasites: broad evidence for the dilution effect. Proceedings of the National Academy of Sciences of the United States of America 112, 8667-8671. doi: 10.1073/pnas.1506279112. Clements, A. C. A., Moyeed, R. and Brooker, S. (2006). Bayesian geostatistical prediction of the intensity of infection with Schistosoma mansoni in East Africa. Parasitology 133, 711-719.

Collins, W.E. (2012). Plasmodium knowlesi: a malaria parasite of monkeys and humans. Annual Review of Entomology 57, 107-121.

Cox-Singh, J. (2012). Zoonotic malaria: Plasmodium knowlesi, an emerging pathogen. Current Opinion in Infectious Diseases 25, 530-536.

Cox-Singh, J. and Singh, B. (2008). Knowlesi malaria: newly emergent and of public health importance? Trends in Parasitology 24, 406-410.

Cox-Singh, J., Davis, T. M. E., Lee, K.-S., Shamsul, S. S. G. Matusop, A., Ratnam, S., Rahman, H. A., Conway, D. J. and Singh, B. (2008). Plasmodium knowlesi malaria in humans is widely distributed and potentially life threatening. Clinical Infectious Diseases 46, 165-171.

Cramer, J.P. (2015). Plasmodium knowlesi malaria: overview focussing on travel-associated infections. Current Infectious Disease Reports 17, 8. doi: 10.1007/s11908-015-0469-6.

Dalrymple, U., Mappin, B. and Gething, P.W. (2015). Malaria mapping: understanding the global endemicity of falciparum and vivax malaria. BMC Medicine 13, 140.

Daneshvar, C., Davis, T.M. E., Cox-Singh, J., Rafa'ee, M.Z., Zakaria, S. K., Divis, P. C. S. and Singh, B. (2009). Clinical and laboratory features of human Plasmodium knowlesi infection. Clinical Infectious Diseases 49, 852-860.

De Castro, M. C., Monte-Mór, R. L., Sawyer, D. O. and Singer, B. H. (2006). Malaria risk on the Amazon frontier. Proceedings of the National Academy of Sciences of the United States of America 103, 2452-2457.

Diekmann, O., Heesterbeek, J. A. P. and Roberts, M. G. (2010). The construction of next-generation matrices for compartmental epidemic models. Fournal of the Royal Society, Interface 7, 873-885.

Diggle, P. J., Thomson, M. C., Christensen, O.F., Rowlingson, B., Obsomer, V., Gardon, J., Wanji, S., Takougang, I., Enyong, P., Kamgno, J., Remme, J.H., Boussinesq, M. and Molyneux, D. H. (2007). Spatial modelling and the prediction of Loa loa risk: decision making under uncertainty. Annals of Tropical Medicine and Parasitology 101, 499-509.

Divis, P.C.S., Singh, B., Anderios, F., Hisam, S., Matusop, A., Kocken, C. H., Assefa, S. A., Duffy, C. W. and Conway, D. J. (2015). Admixture in humans of two divergent Plasmodium knowlesi populations associated with different macaque host species. PLoS Pathogens 11, e1004888.

Fenton, A. and Pedersen, A. B. (2005). Community epidemiology framework for classifying disease threats. Emerging Infectious Diseases 11, 1815-1821

Ferguson, H.M., Dornhaus, A., Beeche, A., Borgemeister, C., Gottlieb, M., Mulla, M. S., Gimnig, J. E., Fish, D. and Killeen, G. F. (2010). Ecology: a prerequisite for malaria elimination and eradication. PLoS Medicine 7, e1000303.

Fooden, J. (1995). Systematic review of Southeast Asian longtail macaques, Macaca fascicularis (Raffles, [1821]). Fieldiana Zoology 81 (206 pages). Fornace, K. M., Drakeley, C. J., William, T., Espino, F. and Cox, J. (2014). Mapping infectious disease landscapes: unmanned aerial vehicles and epidemiology. Trends in Parasitology 30, 514-519.
Fornace, K. M., Nuin, N. A., Betson, M., Grigg, M. J., William, T., Anstey, N. M., Yeo, T. W., Cox, J., Ying, L. T. and Drakeley, C. J. (2015). Asymptomatic and submicroscopic carriage of Plasmodium knowlesi malaria in household and community members of clinical cases in Sabah, Malaysia. Fournal of Infectious Diseases jiv475. doi: 10.1093/infdis/jiv475. Fornace, K. M., Abidin, T.R., Alexander, N., Brock, P.M., Grigg, M. J., Murphy, A., William, T., Menon, J., Drakeley, C. J. and Cox, J. (2016). Association between landscape factors and spatial patterns of emergent Plasmodium knowlesi infections in Sabah, Malaysia. Emerging Infectious Diseases 22. http://dx.doi.org/10.3201/eid2202.150656. Gething, P. W., Patil, A. P., Smith, D. L., Guerra, C. A., Elyazar, I. R. F., Johnston, G. L., Tatem, A. J. and Hay, S. I. (2011). A new world malaria map: Plasmodium falciparum endemicity in 2010. Malaria 7ournal 10, 378

Gilbert, M., Golding, N., Zhou, H., Wint, G. R. W., Robinson, T.P., Tatem, A. J., Lai, S., Zhou, S., Jiang, H., Guo, D., Huang, Z., Messina, J.P., Xiao, X., Linard, C., Van Boeckel, T. P., Martin, V., Bhatt, S., Gething, P. W., Farrar, J. J., Hay, S. I. and Yu, H. (2014) Predicting the risk of avian influenza A H7N9 infection in live-poultry markets across Asia. Nature Communications 5, 4116.

Godfray, H. C. J. (2013). Mosquito ecology and control of malaria. Fournal of Animal Ecology 82, 15-25.

Griffin, J. T., Hollingsworth, T.D., Okell, L.C., Churcher, T.S., White, M., Hinsley, W., Bousema, T., Drakeley, C. J., Ferguson, N. M., Basáñez, M.-G. and Ghani, A. C. (2010). Reducing Plasmodium falciparum malaria transmission in Africa: a model-based evaluation of intervention strategies. PLoS Medicine 7. doi: 10.1371/ journal.pmed.1000324.

Grigg, M. J., William, T., Drakeley, C. J., Jelip, J., Seidlein, L., Von Barber, B. E., Fornace, K. M., Anstey, N. M., Yeo, T. W. and Cox, J. (2014a). Factors that are associated with the risk of acquiring Plasmodium knowlesi malaria in Sabah, Malaysia: a case-control study protocol. BMY Open 4, e006004.

Grigg, M. J., William, T., Dhanaraj, P., Menon, J., Barber, B. E., von Seidlein, L., Rajahram, G., Price, R. N., Anstey, N. M. and Yeo, T. W. (2014b). A study protocol for a randomised open-label clinical trial of artesunate-mefloquine versus chloroquine in patients with non-severe Plasmodium knowlesi malaria in Sabah, Malaysia (ACT KNOW trial). $B M F$ Open 4, e006005.

Grimes, J. E. T. and Templeton, M. R. (2015). Geostatistical modelling of schistosomiasis prevalence. The Lancet Infectious Diseases 15, 869-870. Gubler, D. J. (2004). The changing epidemiology of yellow fever and dengue, 1900 to 2003: full circle? Comparative Immunology, Microbiology and Infectious Diseases 27, 319-330.

Guerra, C., Snow, R. and Hay, S. (2006). A global assessment of closed forests, deforestation and malaria risk. Annals of Tropical Medicine and Parasitology 100, 189-204.

Hambali, K. A., Ismail, A. H. and Zulkifli, S. Y. Z. (2012). Humanmacaque conflict and pest behaviors of Long-tailed macaques (Macaca fascicularis) in Kuala Selangor Nature Park. Tropical Natural History 12, 189-205.

Hansen, M. C., Potapov, P.V., Moore, R., Hancher, M., Turubanova, S. A., Tyukavina, A., Thau, D., Stehman, S. V., Goetz, S. J., Loveland, T. R., Kommareddy, A., Egorov, A., Chini, L., Justice, C. O. and Townshend, J. R. G. (2013). Highresolution global maps of 21 st century forest cover change. Science $\mathbf{3 4 2}$, 850-853.

Hartemink, N., Vanwambeke, S. O., Purse, B. V., Gilbert, M. and Van Dyck, H. (2014). Towards a resource-based habitat approach for spatial modelling of vector-borne disease risks. Biological Reviews 90, 1151-1162. doi: 10.1111/brv.12149.

Hay, S. I., Guerra, C. A., Gething, P. W., Patil, A. P., Tatem, A. J., Noor, A. M., Kabaria, C.W., Manh, B.H., Elyazar, I. R.F., Brooker, S., Smith, D. L., Moyeed, R. A. and Snow, R. W. (2009). A world malaria map: Plasmodium falciparum endemicity in 2007. PLoS Medicine 6, 0286-0302.

Hay, S. I., Battle, K. E., Pigott, D. M., Smith, D. L., Moyes, C. L., Bhatt, S., Brownstein, J. S., Collier, N., Myers, M. F., George, D. B. and Gething, P.W. (2013). Global mapping of infectious disease. Philosophical Transactions of the Royal Society of London B 368, 20120250. Haydon, D. T., Cleaveland, S., Taylor, L. H. and Laurenson, M. K. (2002). Identifying reservoirs of infection: a conceptual and practical challenge. Emerging Infectious Diseases 8, 1468-1473.

Heesterbeek, J. A.P. and Roberts, M. G. (2015). How mathematical epidemiology became a field of biology: a commentary on Anderson and May (1981) "The population dynamics of microparasites and their invertebrate hosts." Philosophical Transactions of the Royal Society of London B 370, 20140307. 
Heesterbeek, H., Anderson, R. M., Andreasen, V., Bansal, S., Angelis, D. De., Dye, C., Eames, K. T. D., Edmunds, W. J., Frost, S. D. W., Funk, S., Hollingsworth, T.D., House, T., Isham, V., Klepac, P., Lessler, J., Lloyd-smith, J. O., Metcalf, C. J. E., Mollison, D., Pellis, L., Pulliam, J. R. C., Roberts, M. G., Viboud, C. and Newton, I. (2015). Modeling infectious disease dynamics in the complex landscape of global health. Science 347, aaa4339. doi: 10.1126/ science.aaa4339.

Helb, D. A., Tetteh, K. K. A., Felgner, P. L., Skinner, J., Hubbard, A., Arinaitwe, E., Mayanja-Kizza, H., Ssewanyana, I., Kamya, M. R., Beeson, J. G., Tappero, J., Smith, D. L., Crompton, P. D., Rosenthal, P. J., Dorsey, G., Drakeley, C. J. and Greenhouse, B. (2015). Novel serologic biomarkers provide accurate estimates of recent Plasmodium falciparum exposure for individuals and communities. Proceedings of the National Academy of Sciences of the United States of America 112, E4438-E4447. doi: 10.1073/pnas.1501705112.

Imai, N., White, M. T., Ghani, A.C. and Drakeley, C. J. (2014). Transmission and control of Plasmodium knowlesi: a mathematical modelling study. PLoS Neglected Tropical Diseases 8, e2978.

Jeslyn, W. P. S., Huat, T. C., Vernon, L., Irene, L. M. Z., Sung, L. K., Jarrod, L. P., Singh, B. and Ching, N. L. (2011). Molecular epidemiological investigation of Plasmodium knowlesi in humans and macaques in Singapore. Vector-borne and Zoonotic Diseases 11, 131-135.

Jiram, A. I., Vythilingam, I., NoorAzian, Y.M., Yusof, Y.M., Azahari, A. H. and Fong, M.-Y. (2012). Entomologic investigation of Plasmodium knowlesi vectors in Kuala Lipis, Pahang, Malaysia. Malaria Fournal 11, 213.

Johnson, P. T. J., de Roode, J. C. and Fenton, A. (2015). Why infectious disease research needs community ecology. Science 349, 1259504-1259504. Kantele, A. and Jokiranta, T. S. (2011). Review of cases with the emerging fifth human malaria parasite, Plasmodium knowlesi. Clinical Infectious Diseases 52, 1356-1362.

Karesh, W. B., Dobson, A., Lloyd-Smith, J. O., Lubroth, J., Dixon, M. A., Bennett, M., Aldrich, S., Harrington, T., Formenty, P., Loh, E. H., Machalaba, C. C., Thomas, M. J. and Heymann, D. L. (2012). Ecology of zoonoses: natural and unnatural histories. Lancet 380, 1936-1945.

Keesing, B. F. and Ostfeld, R. S. (2015). Is biodiversity good for your health? Science 349, 235-236.

Killeen, G. F., Seyoum, A., Gimnig, J.E., Stevenson, J. C., Drakeley, C. J. and Chitnis, N. (2014). Made-to-measure malaria vector control strategies: rational design based on insecticide properties and coverage of blood resources for mosquitoes. Malaria Fournal 13, 146. King, A. A., Magpantay, F. M. G., Celle, M. D. De and Rohani, P. (2015). Avoidable errors in the modelling of outbreaks of emerging pathogens, with special reference to Ebola. Proceedings of the Royal Society B Biological Sciences 282, 20150347.

Lai, Y.-S., Biedermann, P., Ekpo, U.F., Garba, A., Mathieu, E., Midzi, N., Mwinzi, P., N'Goran, E. K., Raso, G., Assaré, R. K., Sacko, M., Schur, N., Talla, I., Tchuenté, L.-A. T., Touré, S., Winkler, M. S., Utzinger, J. and Vounatsou, P. (2015). Spatial distribution of schistosomiasis and treatment needs in sub-Saharan Africa: a systematic review and geostatistical analysis. The Lancet Infectious Diseases 15, 927-940

Lambin, E. F., Tran, A., Vanwambeke, S. O., Linard, C. and Soti, V. (2010). Pathogenic landscapes: interactions between land, people, disease vectors, and their animal hosts. International Fournal of Health Geographics 9, 54

Langner, A., Miettinen, J. and Siegert, F. (2007). Land cover change 2002-2005 in Borneo and the role of fire derived from MODIS imagery. Global Change Biology 13, 2329-2340.

Lau, C. L., Clements, A. C. A., Skelly, C., Dobson, A. J., Smythe, L. D. and Weinstein, P. (2012). Leptospirosis in American Samoa - estimating and mapping risk using environmental data. PLoS Neglected Tropical Diseases 6, e1669.

Lee, K.-S., Cox-Singh, J. and Singh, B. (2009a). Morphological features and differential counts of Plasmodium knowlesi parasites in naturally acquired human infections. Malaria Fournal 8, 73.

Lee, K.-S., Cox-Singh, J., Brooke, G., Matusop, A. and Singh, B. (2009b). Plasmodium knowlesi from archival blood films: further evidence that human infections are widely distributed and not newly emergent in Malaysian Borneo. International fournal for Parasitology 39, 1125-1128. Lee, K.-S., Divis, P. C. S., Zakaria, S. K., Matusop, A., Julin, R. A., Conway, D. J., Cox-Singh, J. and Singh, B. (2011). Plasmodium knowlesi: reservoir hosts and tracking the emergence in humans and macaques. PLoS Pathogens 7, e1002015.

Lloyd-Smith, J. O., Schreiber, S. J., Kopp, P. E. and Getz, W. M. (2005). Superspreading and the effect of individual variation on disease emergence. Nature 438, 355-359.
Lloyd-Smith, J. O., George, D., Pepin, K. M., Pitzer, V. E., Pulliam, J. R. C., Dobson, A. P., Hudson, P. J. and Grenfell, B. T. (2009). Epidemic dynamics at the human-animal interface. Science 326, 1362-1367. Lloyd-Smith, J. O., Funk, S., McLean, A. R., Riley, S. and Wood, J. L. N. (2014). Nine challenges in modelling the emergence of novel pathogens. Epidemics

Macdonald, G. (1957). The Epidemiology and Control of Malaria. Oxford University Press.

Macdonald, G., Cuellar, C. B. and Foll, C. V. (1968). The dynamics of malaria. Bulletin of the World Health Organization 38, 743-755.

Magalhães, R. J. S., Clements, A.C. A., Patil, A.P., Gething, P.W. and Brooker, S. (2011). The applications of model-based geostatistics in helminth epidemiology and control. Advances in Parasitology 74, 267-296.

Mandal, S., Sarkar, R. R. and Sinha, S. (2011). Mathematical models of malaria - a review. Malaria fournal 10, 202

Marchand, R. P., Culleton, R., Maeno, Y., Quang, N. T. and Nakazawa, S. (2011). Co-infections of Plasmodium knowlesi, $P$. falciparum, and $P$. vivax among Humans and Anopheles dirus Mosquitoes, Southern Vietnam. Emerging Infectious Diseases 17, 1232 1239

Matthiopoulos, J., Hebblewhite, M. and Aarts, G. (2011). Generalized functional responses for species distributions. Ecology 92, 583-589. Matthiopoulos, J., Fieberg, J., Aarts, G., Beyer, H. L. and Morales, J. M. (2015). Establishing the link between habitat-selection and animal population dynamics. Ecological Monographs 85, 413-436.

McCallum, H. I. (2015). Lose biodiversity, gain disease. Proceedings of the National Academy of Sciences of the United States of America 112, 8523-8524. doi: 10.1073/pnas.1510607112.

McKenzie, F.E. (2000). Why model malaria? Parasitology Today $\mathbf{1 6}$, 511-516.

Messina, J. P., Pigott, D. M., Golding, N., Duda, K. A., Brownstein, J. S., Weiss, D. J., Gibson, H., Robinson, T. P., Gilbert, M., William Wint, G. R., Nuttall, P. A., Gething, P. W., Myers, M. F., George, D. B. and Hay, S. I. (2015). The global distribution of crimean-congo hemorrhagic fever. Transactions of The Royal Society of Tropical Medicine and Hygiene 109, 503-513. doi: 10.1093/trstmh/trv050.

Meyers, L. A., Pourbohloul, B., Newman, M. E. J., Skowronski, D. M. and Brunham, R. C. (2005). Network theory and SARS: predicting outbreak diversity. Fournal of Theoretical Biology 232, 71-81

Millar, S. B. and Cox-Singh, J. (2015). Human infections with Plasmodium knowlesi-zoonotic malaria. Clinical Microbiology and Infection 21, 640-648.

Mills, H. L. and Riley, S. (2014). The spatial resolution of epidemic peaks. PLoS Computational Biology 10, e1003561.

Morales, J. M., Moorcroft, P.R., Matthiopoulos, J., Frair, J. L., Kie, J. G., Powell, R. A., Merrill, E. H. and Haydon, D. T. (2010). Building the bridge between animal movement and population dynamics. Philosophical Transactions of the Royal Society of London B 365, 2289-2301. Moyes, C. L., Henry, A. J., Golding, N., Huang, Z., Singh, B., Baird, J. K., Newton, P. N., Huffman, M., Duda, K. A., Drakeley, C. J., Elyazar, I. R. F., Anstey, N. M., Chen, Q., Zommers, Z., Bhatt, S., Gething, P. W. and Hay, S. I. (2014). Defining the geographical range of the Plasmodium knowlesi reservoir. PLoS Neglected Tropical Diseases 8 , e2780.

Mylne, A. Q. N., Pigott, D. M., Longbottom, J., Shearer, F., Duda, K. A., Messina, J. P., Weiss, D. J., Moyes, C. L., Golding, N. and Hay, S. I. (2015). Mapping the zoonotic niche of Lassa fever in Africa. Transactions of the Royal Society of Tropical Medicine and Hygiene 109, 483-492.

Noviyanti, R., Coutrier, F., Utami, R.A.S., Trimarsanto, H., Tirta, Y. K., Trianty, L., Kusuma, A., Sutanto, I., Kosasih, A., Kusriastuti, R., Hawley, W. A., Laihad, F., Lobo, N., Marfurt, J., Clark, T. G., Price, R. N. and Auburn, S. (2015). Contrasting transmission dynamics of co-endemic Plasmodium vivax and $P$. falciparum: implications for malaria control and elimination. PLoS Neglected Tropical Diseases 9, e0003739.

Overgaard, H. J., Ekbom, B., Suwonkerd, W. and Takagi, M. (2003). Effect of landscape structure on anopheline mosquito density and diversity in northern Thailand: implications for malaria transmission and control. Landscape Ecology 18, 605-619.

Patil, A. P., Gething, P. W., Piel, F. B. and Hay, S. I. (2011). Bayesian geostatistics in health cartography: the perspective of malaria. Trends in Parasitology 27, 246-253.

Patz, J. A., Graczyk, T. K., Geller, N. and Vittor, A. Y. (2000). Effects of environmental change on emerging parasitic diseases. International Fournal for Parasitology 30, 1395-1405.

Perkins, T. A., Scott, T. W., Le Menach, A. and Smith, D. L. (2013). Heterogeneity, mixing, and the spatial scales of mosquito-borne pathogen transmission. PLoS Computational Biology 9, e1003327. 
Petney, T., Sithithaworn, P., Satrawaha, R., Grundy-Warr, C., Andrews, R., Wang, Y.-C. and Feng, C.-C. (2009). Potential malaria reemergence, Northestern Thailand. Emerging Infectious Diseases 15, 1330 1331

Pigott, D. M., Bhatt, S., Golding, N., Duda, K. A., Battle, K. E., Brady, O. J., Messina, J.P., Balard, Y., Bastien, P., Pratlong, F., Brownstein, J.S., Freifeld, C.C., Mekaru, S. R., Gething, P.W., George, D. B., Myers, M. F., Reithinger, R. and Hay, S. I. (2014). Global distribution maps of the leishmaniases. eLife 3, 1-21

Pigott, D. M., Howes, R. E., Wiebe, A., Battle, K. E., Golding, N., Gething, P.W., Dowell, S.F., Farag, T.H., Garcia, A. J., Kimball, A. M., Krause, L. K., Smith, C. H., Brooker, S. J., Kyu, H. H., Vos, T., Murray, C. J. L., Moyes, C. L. and Hay, S. I. (2015). Prioritising infectious disease mapping. PLoS Neglected Tropical Diseases 9, e0003756.

Pullan, R. L., Sturrock, H. J.W., Soares Magalhães, R. J. Clements, A. C. A. and Brooker, S. J. (2012). Spatial parasite ecology and epidemiology: a review of methods and applications. Parasitology 139, 1870-1887.

Rajahram, G. S., Barber, B. E., William, T., Menon, J., Anstey, N. M. and Yeo, T.W. (2012). Deaths due to Plasmodium knowlesi malaria in Sabah, Malaysia: association with reporting as Plasmodium malariae and delayed parenteral artesunate. Malaria fournal 11, 284.

Ramasamy, R. (2014). Zoonotic malaria - global overview and research and policy needs. Frontiers in Public Health 2, 1-7.

Raso, G., Schur, N., Utzinger, J., Koudou, B. G., Tchicaya, E.S., Rohner, F., N'Goran, E. K., Silué, K.D., Matthys, B., Assi, S., Tanner, M. and Vounatsou, P. (2012). Mapping malaria risk among children in Côte d'Ivoire using Bayesian geo-statistical models. Malaria fournal 11, 160.

Reiner, R. C., Perkins, T. A., Barker, C.M., Niu, T., Chaves, L.F., Ellis, A. M., George, D. B., Le Menach, A., Pulliam, J. R. C., Bisanzio, D., Buckee, C., Chiyaka, C., Cummings, D. A. T. Garcia, A. J., Gatton, M. L., Gething, P.W., Hartley, D. M., Johnston, G., Klein, E. Y., Michael, E., Lindsay, S. W., Lloyd, A. L., Pigott, D. M., Reisen, W. K., Ruktanonchai, N., Singh, B. K., Tatem, A. J., Kitron, U., Hay, S. I., Scott, T. W. et al. (2013). A systematic review of mathematical models of mosquito-borne pathogen transmission: 1970-2010. Fournal of the Royal Society, Interface 10, 20120921. doi: 10.1098/rsif.2012.0921.

Riley, S. (2007). Large-scale models of infectious disease. Science $\mathbf{3 1 6}$, 1298-1301.

Riley, E. P. (2008). Ranging patterns and habitat use of Sulawesi Tonkean macaques (Macaca tonkeana) in a human-modified habitat. American Fournal of Primatology 70, 670-679.

Riley, S., Eames, K., Isham, V., Mollison, D. and Trapman, P. (2015). Five challenges for spatial epidemic models. Epidemics 10, 68-71.

Singh, M., Kumara, H. N., Kumar, M. A. and Sharma, A. K. (2001). Behavioural responses of Lion-tailed macaques (Macaca silenus) to a changing habitat in a tropical rain forest fragment in the Western Ghats, India. Folia Primatologica 72, 278-291.

Singh, B., Sung, L. K., Matusop, A., Radhakrishnan, A., Shamsul, S. S. G., Cox-Singh, J., Thomas, A. and Conway, D. J. (2004). A large focus of naturally acquired Plasmodium knowlesi infections in human beings. Lancet 363, 1017-1024.

Smith, T. A. (2008). Estimation of heterogeneity in malaria transmission by stochastic modelling of apparent deviations from mass action kinetics. Malaria Fournal 7, 12.

Smith, D. L., Battle, K. E., Hay, S. I., Barker, C. M., Scott, T. W. and McKenzie, F. E. (2012). Ross, macdonald, and a theory for the dynamics and control of mosquito-transmitted pathogens. PLoS Pathogens 8, e1002588.

Smith, D. L., Perkins, T.A., Reiner, R. C., Barker, C. M., Niu, T., Chaves, L.F., Ellis, A. M., George, D. B., Le Menach, A., Pulliam, J.R.C., Bisanzio, D., Buckee, C., Chiyaka, C., Cummings, D. A.T., Garcia, A. J., Gatton, M.L., Gething, P.W., Hartley, D. M., Johnston, G., Klein, E. Y., Michael, E., Lloyd, A. L., Pigott, D. M., Reisen, W. K., Ruktanonchai, N., Singh, B. K., Stoller, J., Tatem, A. J., Kitron, U. et al. (2014). Recasting the theory of mosquito-borne pathogen transmission dynamics and control. Transactions of the Royal Society of Tropical Medicine and Hygiene 108, 185-197. Streicker, D. G., Fenton, A. and Pedersen, A. B. (2013). Differential sources of host species heterogeneity influence the transmission and control of multihost parasites. Ecology Letters 16, 975-984.

Tan, C. H., Vythilingam, I., Matusop, A., Chan, S. T. and Singh, B. (2008). Bionomics of Anopheles latens in Kapit, Sarawak, Malaysian Borneo in relation to the transmission of zoonotic simian malaria parasite Plasmodium knowlesi. Malaria Fournal 7, 52.
Van den Eede, P., Vythilingam, I., Ngo, D. T., Nguyen, V. H., Le, X. H., D'Alessandro, U. and Erhart, A. (2010). Plasmodium knowlesi malaria in Vietnam: some clarifications. Malaria fournal 9, 20

Van Hellemond, J. J., Rutten, M., Koelewijn, R., Zeeman, A. M., Verweij, J. J., Wismans, P. J., Kocken, C. H. and van Genderen, P. J. J. (2009). Human Plasmodium knowlesi infection detected by rapid diagnostic tests for malaria. Emerging Infectious Diseases 15, 1478-1480.

Vasilakis, N., Cardosa, J., Hanley, K. A., Holmes, E. C. and Weaver, S. C. (2011). Fever from the forest: prospects for the continued emergence of sylvatic dengue virus and its impact on public health. Nature Reviews Microbiology 9, 532-541.

Viana, M., Mancy, R., Biek, R., Cleaveland, S., Cross, P. C., LloydSmith, J. O. and Haydon, D. T. (2014). Assembling evidence for identifying reservoirs of infection. Trends in Ecology \& Evolution 29, 270-279. Vounatsou, P., Raso, G., Tanner, M., N'goran, E. and Utzinger, J. (2009). Bayesian geostatistical modelling for mapping schistosomiasis transmission. Parasitology 136, 1695-1705.

Vythilingam, I. (2012). Plasmodium knowlesi and Wuchereria bancrofti their vectors and challenges for the future. Frontiers in Physiology 3, 115.

Vythilingam, I., Tan, C. H., Asmad, M., Chan, S. T., Lee, K. S. and Singh, B. (2006). Natural transmission of Plasmodium knowlesi to humans by Anopheles latens in Sarawak, Malaysia. Transactions of the Royal Society of Tropical Medicine and Hygiene 100, 1087-1088.

Vythilingam, I., Noorazian, Y.M., Huat, T.C., Jiram, A. I., Yusri, Y. M., Azahari, A.H., Norparina, I., Noorrain, A. and Lokmanhakim, S. (2008). Plasmodium knowlesi in humans, macaques and mosquitoes in peninsular Malaysia. Parasites $\Xi^{\circ}$ Vectors 1, 26.

Vythilingam, I., Lim, Y. Al., Venugopalan, B., Ngui, R., Leong, C. S., Wong, M. L., Khaw, L., Goh, X., Yap, N., Sulaiman, W.Y.W., Jeffery, J., Zawiah, A. G. C., Nor Aszlina, I., Sharma, R. S., Yee Ling, L. and Mahmud, R. (2014). Plasmodium knowlesi malaria an emerging public health problem in Hulu Selangor, Selangor, Malaysia (20092013): epidemiologic and entomologic analysis. Parasites $\mathcal{F}^{\circ}$ Vectors 7, 436. Wallace, D. I., Southworth, B.S., Shi, X., Chipman, J.W. and Githeko, A. K. (2014). A comparison of five malaria transmission models: benchmark tests and implications for disease control. Malaria fournal 13, 268.

Wardrop, N. A., Kuo, C. C., Wang, H. C., Clements, A. C. A., Lee, P. F. and Atkinson, P. M. (2013). Bayesian spatial modelling and the significance of agricultural land use to scrub typhus infection in Taiwan. Geospatial Health 8, 229-239.

Wardrop, N. A., Geary, M., Osborne, P. E. and Atkinson, P. M. (2014). Interpreting predictive maps of disease: highlighting the pitfalls of distribution models in epidemiology. Geospatial Health 9, 237-246.

World Health Organisation (2014). WHO Global Malaria Program: World Malaria Report 2014. World Health Organisation, Geneva, Switzerland. http://www.who.int/malaria/publications/world_malaria_report_2014/report/en/

William, T., Menon, J., Rajahram, G., Chan, L., Ma, G., Donaldson, S., Khoo, S., Fredrick, C., Jelip, J., Anstey, N. M. and Yeo, T. W. (2011). Severe Plasmodium knowlesi malaria in a tertiary care hospital. Emerging Infectious Diseases 17, 1248-1255.

William, T., Rahman, H. A., Jelip, J., Ibrahim, M. Y., Menon, J., Grigg, M. J., Yeo, T. W., Anstey, N. M. and Barber, B. E. (2013). Increasing incidence of Plasmodium knowlesi malaria following control of P. falciparum and P. vivax malaria in Sabah, Malaysia. PLoS Neglected Tropical Diseases 7, e2026.

William, T., Jelip, J., Menon, J., Anderios, F., Mohammad, R., Awang Mohammad, T. A., Grigg, M. J., Yeo, T. W., Anstey, N. M. and Barber, B. E. (2014). Changing epidemiology of malaria in Sabah, Malaysia: increasing incidence of Plasmodium knowlesi. Malaria fournal 13, 390 .

Wong, M. L., Chua, T. H., Leong, C. S., Khaw, L. T., Fornace, K. M., Wan-Sulaiman, W. Y., William, T., Drakeley, C. J., Ferguson, H. M. \& Vythilingam, I. (2015). Seasonal and spatial dynamics of the primary vector of Plasmodium knowlesi within a major transmission focus in Sabah, Malaysia. PLoS Neglected Tropical Diseases 9, e0004135.

Wood, K. A., Stillman, R. A. and Goss-Custard, J. D. (2015). Cocreation of individual-based models by practitioners and modellers to inform environmental decision-making. Fournal of Applied Ecology 52, 810-815. doi: 10.1111/1365-2664.12419.

Yakob, L., Bonsall, M. B. and Yan, G. (2010). Modelling knowlesi malaria transmission in humans: vector preference and host competence. Malaria Fournal 9, 329.

Yusof, R., Lau, Y.-L., Mahmud, R., Fong, M.-Y., Jelip, J., Ngian, H. U., Mustakim, S., Mat Hussin, H., Marzuki, N. and Mohd Ali, M. (2014). High proportion of knowlesi malaria in recent malaria cases in Malaysia. Malaria Fournal 13, 168. 